\title{
El sistema bancario de Corea del Sur desde la crisis asiática, 1997-2004
}

$\mathrm{E}$ n noviembre de 1997 Corea del Sur fue arrastrada en la crisis asiática, y tuvo rápidamente que firmar un acuerdo con el Fondo Monetario Internacional (FMI) a través del cual recibiría un paquete de apoyo financiero internacional. En consecuencia, el país emprendió desde finales de dicho año un programa de estabilización con medidas para reformar conjuntamente el sector corporativo y el sistema financiero, cuya situación se hallaba estrechamente unida por una pesada cadena de préstamos vencidos, y proseguir con la liberalización de la economía. Las políticas aplicadas a partir de diciembre de 1997 fueron introducidas rápidamente y con mucha decisión, con la finalidad de producir señales claras capaces de restablecer la confianza con la mayor rapidez. A grandes rasgos se proponían "reemplazar el enfoque dirigista vigente en el pasado, por un paradigma fundamentado en el mercado". ${ }^{1}$

Estas políticas, ajustadas en 1998 para aminorar sus efectos recesivos, permitieron a Corea retomar rápidamente la senda del crecimiento económico, contribuyeron a transformar el sector empresarial del país y han introducido cambios notables en el sistema financiero. Los vínculos estrechos que éste mantenía con las grandes empresas y con las autoridades se han debilitado y de alguna manera el sistema se ha acercado más al modelo vigente en las principales economías desarrolladas, sin que estas transformaciones estén del todo acabadas.

Este artículo se propone revisar los rasgos principales de la evolución del sistema bancario coreano entre 1997 y 2004 . Para ello, se presentan brevemente en una primera sec-

* Profesora investigadora del Departamento de Estudios del Pacífico, de la Universidad de Guadalajara, e investigadora del SNI. ción el contexto macroeconómico y las reformas aplicadas tanto al sector corporativo como a la esfera financiera. En una segunda sección se analizan tres cambios mayores que ha vivido el sistema bancario: 1) la concentración producida por el proceso de cierre y de fusiones de entidades efectuado bajo la conducción de las autoridades, 2) la evolución de la participación accionaria del gobierno y de la inversión extranjera en el capital del sistema, 3) la diversificación de la oferta de crédito hacia las familias y las pequeñas y medianas empresas, seguida de la reciente crisis de pago en el sector de las tarjetas de crédito.

\section{Estabilización, reformas y reestructu- ración financiera}

En el muy corto plazo, el programa aplicado en Corea a partir de diciembre de 1997 se fijaba como objetivo central estabilizar el tipo de cambio y reconstituir las reservas internacionales; para ello, planteaba una combinación de medidas típica de los programas diseñados por el FMI, es decir, que buscaba contraer la demanda interna a través de una política monetaria restrictiva y del mantenimiento de la austeridad fiscal prevaleciente antes de la crisis. ${ }^{2}$

\section{El contexto macroeconómico}

En sus inicios este programa tuvo resultados excesivamente recesivos para Corea ${ }^{3}$ que mostró un fuerte declive en todos sus indicadores macroeconómicos, así como en el nivel de empleo en 1998. En particular, la política de tasas de interés altas ${ }^{4}$ que se impuso para estabilizar el tipo de cambio tuvo efectos colaterales en extremo dañinos, pues profundizó el declive económico al deteriorar aún más la situación financiera de las empresas sobreendeudadas: la cartera vencida, que al- 
canzaba $13 \%$ de los créditos bancarios en diciembre de 1997, ya se había elevado a $22 \%$ en junio de 1998. Combinada con el fortalecimiento de los requisitos de calidad de la cartera impuestos simultáneamente a los bancos y con el mayor riesgo que presentaban numerosos deudores, esta política contribuyó en contraer más la oferta de crédito, creando un "credit crunch", es decir, una escasez aguda de financiamiento.

Estas políticas restrictivas fueron revertidas con cierta rapidez. En cuanto se estabilizó la moneda nacional, las autoridades lograron el visto bueno del FMI para modificar las políticas monetaria y fiscal. Esta última se tornó rápidamente anticíclica, desde fines de diciembre de $1997,{ }^{5}$ mientras que la primera era relajada más tardíamente, abandonando su carácter contractivo a partir de mayo de 1998, lo cual autorizó desde esta fecha la disminución rápida de las tasas de interés: en junio de 1998 se situaban en un nivel menor al que prevalecía antes de la crisis, el cual siguió bajando a lo largo de 1999 para estimular la actividad y facilitar una disminución de las razones de endeudamiento de las empresas. ${ }^{6}$

Estas medidas fueron acompañadas de estrategias específicas destinadas a favorecer el acceso al crédito de las pequeñas y medianas empresas (PME). Ciertamente, estas políticas de estimulación de la actividad económica ${ }^{7}$ jugaron un papel determinante en la rápida y sostenida recuperación coreana: después de una profunda contracción en 1998 (-6.7\% del crecimiento del PIB), la economía creció con rapidez durante dos años (10.9\% y $9.3 \%$, respectivamente en 1999 y 2000), bajando su ritmo más adelante, con alrededor de $3 \%$ en 2001 y 2003. Sin duda, este buen desempeño macroeconómico facilitó a su vez los procesos de reestructuración corporativa y financiera al mejorar la situación de la mayoría de las empresas.

\section{La reestructura ción corporativa y financiera}

Las dos vertientes centrales de las reformas estructurales introducidas a partir de 1997 se hallan estrechamente vinculadas: tanto la reforma del sistema financiero, que incluye la reestructuración de las instituciones en problemas, como la reforma empresarial fueron emprendidas bajo la responsabilidad de una Comisión de Supervisión Financiera (Financial Supervisory Commission, FSC), una institución pública independiente creada $e x$ profeso. En el ámbito corporativo, la reestructuración de la deuda de las empresas, la reforma del gobierno corporativo y la liberalización de la inversión extranjera han sido las tareas más importantes planeadas por las autoridades. ${ }^{8}$ Las medidas buscaban fortalecer el poder y la transparencia de los mercados (y a la vez cortar el estrecho y antiguo vínculo conglomerados-Estado autoritario), pero su aplicación requirió una reforzada intervención del Estado, en particular para vencer la fuerte resistencia al cambio de los actores involucrados. ${ }^{9}$

La reestructuración de la deuda corporativa se hizo de manera diferenciada en función del tamaño de las empresas, separándose el trato aplicado a los cinco primeros conglomerados, de los chaebols de rango seis a 64 , y de las PME. ${ }^{10}$ El gobierno elaboró primero el marco en el cual se realizaría la reestructuración de los chaebols medianos, que experimentaban las dificultades más severas, adoptándose un esquema de renegociación de deuda "fuera de cortes" inspirado en el llamado "enfoque de Londres" del Banco de Inglaterra, donde participaban los bancos comerciales 
y el Estado como mediador - y con frecuencia ordenador central- del proceso. ${ }^{11}$ Posteriormente, se analizó la reestructuración de los cinco primeros conglomerados, incitándolos a elaborar un plan de reestructuración que debía ser sometido a la revisión de sus bancos principales; en este proceso también intervinieron activamente las autoridades - amenazando a veces con el recorte del crédito- para promover "desde arriba" fusiones e intercambios de subsidiarias entre conglomerados, con el objetivo de especializarlos en las actividades donde cada uno presentaba mayores ventajas, creando en el mediano o largo plazo "campeones nacionales" competitivos internacionalmente. ${ }^{12}$

En el contexto de esta reestructuración corporativa, la profundización de la liberalización de los flujos financieros con el exterior, y en particular la de la inversión extranjera, persiguió dos objetivos: en el corto plazo, permitir la inyección de liquidez en el sector productivo coreano y a mediano y largo plazo, favorecer una mayor eficiencia de las empresas. ${ }^{13}$ Para ello, el país fue ampliamente abierto a la inversión extranjera directa (IED), se desregularon los mercados locales de dinero y de capitales, así como las transacciones en divisas. ${ }^{14}$
Los resultados más notables de estas medidas fueron una fuerte elevación de las entradas notificadas de IED efectuadas sobre todo en forma de fusiones y adquisiciones de empresas coreanas existentes, así como una mayor participación de inversionistas extranjeros en el mercado accionario, en especial en las compañías más grandes (la participación extranjera en la capitalización de mercado de la bolsa de Seúl se elevó de 19\% del total en 1998 a $37 \%$ en $2001^{15}$ y a $42 \%$ en 2003 , llegando a $50 \%$ del capital en el caso de los chaebols más grandes). ${ }^{16}$ En suma, la inversión extranjera ha participado activamente en la reestructuración del sector industrial coreano, elevándose el grado de control ejercido por entidades foráneas, una tendencia que no siempre es bien recibida en Corea.

En el sistema financiero las medidas combinaron dispositivos de emergencia orientados al rescate o cierre de instituciones en problemas y medidas de liberalización de las operaciones de los intermediarios aunadas a un fortalecimiento de la supervisión y de la reglamentación. Al igual que en el caso de la reestructuración de los chaebols, las medidas incluyeron una activa participación del Estado. La rehabilitación del sistema se realizó bajo la responsabilidad de la Fsc, que estableció una Unidad de Reestructuración Financiera, encargada a su vez de coordinar el conjunto de las

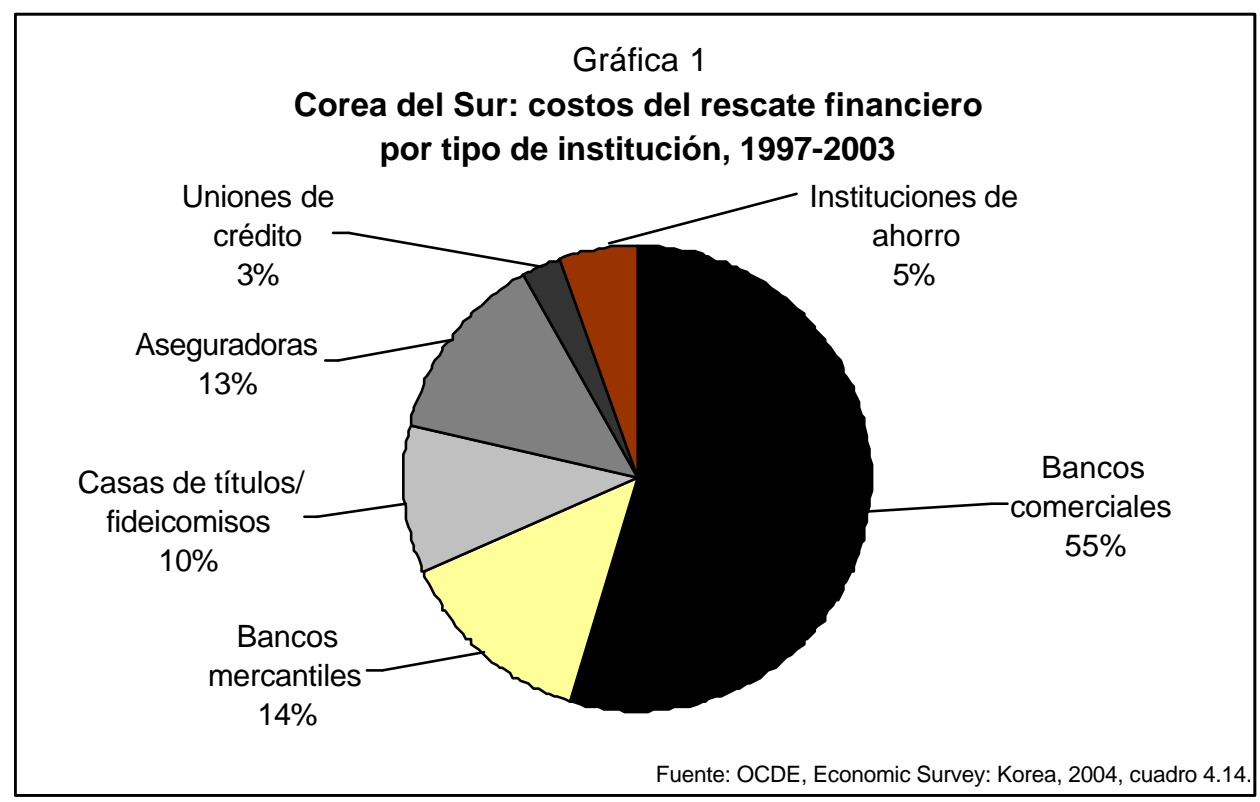


operaciones realizadas por dos instituciones especializadas: la Corporación Coreana de Seguro de Depósito (KDIC, por su sigla en inglés), encargada de devolver los depósitos de instituciones quebradas y de aportar fondos a los programas de capitalización bancaria, y la Corporación Coreana de Gestión de Activos (KAMCO), establecida para adquirir y realizar los activos de mala calidad de las instituciones aseguradas por la garantía de depósito.

En razón de su importancia macroeconómica, el sistema bancario concentró inicialmente las medidas de reestructuración y los recursos financieros, pero después las autoridades tuvieron que desempeñar un papel similar para las demás instituciones que componen la esfera financiera. El balance de los recursos públicos invertidos en el saneamiento del sistema muestra que a finales de 2003 éstos alcanzaban 161 millones de millones de wons, es decir, $22 \%$ del PIB de ese año, ${ }^{17}$ y que $97 \%$ de estos fondos fueron invertidos entre 1997 y 2001. ${ }^{18}$ Fueron dirigidos principalmente hacia la banca comercial $(55 \%$ del total), y en proporciones menores hacia otros intermediarios, entre los cuales destacan los bancos mercantiles ("merchant banks") con $14 \%$ del total, las aseguradoras y las casas de títulos y fideicomisos con respectivamente $13 \%$ y $10 \%$ de los recursos (ver gráfica 1 ). Hasta inicios de 2004 se estimaba que alrededor de 63 millones de millones de wons habían sido recuperados, una proporción no desdeñable pues es cercana al $38 \%$ de los recursos invertidos, ${ }^{19}$ que dejará sin embargo pérdidas importantes al gobierno, las cuales serán absorbidas paulatinamente.

\section{La evolución del sistema financiero}

Con la introducción de este conjunto de medidas, el sistema financiero ha sido transformado profundamente y en varios aspectos. En esta sección analizaremos con detenimiento algunas características sobresalientes: el avance en la concentración del sistema, la evolución de la participación accionaria de entidades de gobierno y de inversionistas extranjeros, y el cambio profundo que se ha dado en la asignación del crédito.

\section{Reestructuración y concentración del sistema}

La reestructuración, que incluyó el cierre de entidades en problemas así como un proceso de fusión de instituciones sobrevivientes, redujo el número de instituciones y creó intermediarios de mayor tamaño (cuadro 1). En el ámbito de la banca comercial, sólo quedaban 19 instituciones en 2003, contra 33 en 1997, y las fusiones llegaron a crear un grupo de tres "megabancos": Kookmin, Shinhan y Hana. ${ }^{20}$ En el ámbito de las instituciones financieras nobancarias (IFNB), la reestructuración ha sido particularmente severa en el caso de los bancos mercantiles, instituciones que se hallaban

Cuadro 1

Corea del Sur: cambios en el número de instituciones financieras, 1997-2003

\begin{tabular}{lrrrrr}
\hline & 1997 & Liquidaciones & Fusiones & Creaciones & 2003 (finales) \\
\hline Bancos & 33 & 5 & 10 & 1 & 19 \\
Sector no-bancario & 2068 & 641 & 153 & 70 & 1344 \\
Bancos mercantiles & 30 & 22 & 7 & 1 & 2 \\
Casas de títulos & 36 & 7 & 3 & 18 & 44 \\
Fideicomisos de inversión & 30 & 6 & 1 & 9 & 32 \\
Aseguradoras & 50 & 11 & 6 & 17 & 50 \\
Uniones de crédito & 1666 & 482 & 107 & 9 & 1086 \\
Instituciones de ahorro & 231 & 102 & 27 & 12 & 114 \\
Arrendadoras & 25 & 11 & 2 & 4 & 16 \\
& & & & & \\
Total & 2101 & 646 & 163 & 71 & 1363 \\
\hline
\end{tabular}

Fuente: OCDE, Economic Survey: Korea, 2004, París, cuadro 4.5, p. 113. 
en la peor situación financiera en razón de los riesgos excesivos asumidos ante la insuficiencia de su reglamentación previa a la crisis (el cierre y las fusiones alcanzaron $97 \%$ de las instituciones en 1997), y en menor medida en el caso de entidades más pequeñas como las de ahorro, arrendadoras y uniones de crédito. Ciertamente, como producto de la expansión de los mercados de títulos, y en particular de los bonos, el sector de las casas de títulos es el único que presenta un crecimiento neto de las instituciones existentes.

\section{La participación pública y extranjera en el capital del sistema}

La segunda honda transformación que ha experimentado el sistema financiero coreano desde la crisis, concierne a la composición del capital de las entidades que lo integran. Entre 1997 y 2004 se produjo un doble movimiento. En un primer momento se dio una elevación sustancial de la participación pública en el capital de las instituciones financieras, en contraparte del esfuerzo de capitalización con fondos públicos: ésta llegó a ser muy elevada en determinados bancos - $94 \%$ para el Banco de
Seúl y la Korea First Bank, dos bancos importantes que fueron intervenidos por las autoridades en diciembre de 1997, 90\% para el Banco Chohung, y 57\% para el Banco Hana-y alcanzó para la banca comercial en su conjunto un nivel de 53\% en $1999 .{ }^{21}$ En un segundo momento, las autoridades han ido disminuyendo su participación y estas privatizaciones, combinadas con la liberalización de la cuenta de capitales, han permitido la entrada de inversionistas extranjeros en el capital del sistema: a mediados de 2003 el gobierno había disminuido su presencia a 38\% del capital bancario; en contraste, la inversión extranjera directa se elevaba de $7 \%$ en 1997 a $27 \%$ del capital de la banca comercial en 2002. ${ }^{22}$ A fines de 2003, las participaciones de ambos actores en los principales bancos del sistema quedaban como lo muestra el cuadro 2 .

Cabe señalar que, en ausencia de inversionistas locales con suficiente capacidad financiera - la inversión de los chaebols en el sistema bancario no está autorizada, debido a los riesgos sistémicos para la esfera financiera y la economía-, importantes paquetes accionarios fueron adquiridos por fondos privados de inversión en capital de origen anglo-

Cuadro 2

Corea del Sur: participación pública e inversión extranjera directa en el sistema bancario (fines de 2003)

\begin{tabular}{|c|c|c|c|c|}
\hline \multirow[t]{2}{*}{ Bancos de alcance nacional } & \multicolumn{2}{|c|}{ Participación pública } & \multicolumn{2}{|c|}{ Inversión extranjera directa } \\
\hline & KDIC & $\begin{array}{l}\text { Otras entidades } \\
\text { públicas }\end{array}$ & Participación & Principales inversionistas \\
\hline Choheung & - & -- & $2.27 \%$ & \\
\hline Woori/a & $86.84 \%$ & -- & -- & \\
\hline Korea First Bank & $48.49 \%$ & $2.95 \%$ & $48.56 \%$ & New Bridge Capital \\
\hline Korea Exchange Bank & & $20.18 \%$ & $71.04 \%$ & Lone Star (51) Commerzbank (14.8) \\
\hline Kookmin & -- & -- & $73.56 \%$ & ING Bank \\
\hline Shinhan & -- & -- & -- & \\
\hline KorAm/ ${ }^{\mathrm{b}}$ & -- & -- & $89.59 \%$ & Carlyle Cons. (36.7) Standard Chartered. (9.7) \\
\hline Hana & $21.66 \%$ & & $43.16 \%$ & Allianz (8.16) \\
\hline \multicolumn{5}{|l|}{ Bancos locales } \\
\hline Daegu & -- & -- & $31.31 \%$ & SSB-Small Capital (5) \\
\hline Pusan & -- & -- & $38.46 \%$ & Capital Research \& Management (10.4) \\
\hline Kwangju/a & $86.84 \%$ & -- & & \\
\hline \multicolumn{5}{|l|}{ Cheju } \\
\hline Jeonbuk & -- & -- & $0.25 \%$ & \\
\hline Kyongnam ${ }^{\text {a }}$ & $86.84 \%$ & -- & & \\
\hline
\end{tabular}


sajón, como Newbridge Capital (Korea First Bank), Lone Star (Korea Exchange Bank) o Carlyle (KorAm), los cuales no tienen en principio vocación de inversionistas mayoritarios de largo plazo. De hecho, Carlyle vendió su participación a Citigroup en febrero de 2004, y Newbridge consideraría vender la que tiene en Korea First en 2005. ${ }^{23}$

La creciente presencia extranjera en el sistema financiero y las elevadas ganancias de los fondos de inversión foráneos han generado cierto malestar en Corea, por lo que las autoridades elaboraron una reforma legal que entrará en vigor en diciembre de 2004 y pondrá mayores requisitos a los fondos de inversión extranjeros que deseen adquirir participaciones en entidades bancarias coreanas. Simultáneamente, la reforma abrirá el mercado local de fondos privados de inversión en capital, al autorizar la creación de fondos coreanos, la cual fomentará una mayor presencia nacional en esta industria. Ello debería cambiar de manera significativa el contexto donde se desarrollarán las privatizaciones necesarias para disminuir la participación accionaria pública en el sistema financiero: en lo que va de 2004 se registraron nuevos desarrollos en este dominio, con la colocación de un paquete accionario representativo de $5.1 \%$ del capital del grupo financiero Woori, todavía controlado por KDIC con más de $80 \%$ de su capital. ${ }^{24}$
La reorientación del crédito y la crisis de las tarjetas

A diferencia de lo ocurrido en crisis financieras de otras economías emergentes, la crisis coreana no ha sido acompañada de manera duradera por una contracción de la monetización o del crédito. Como se mencionó antes en este artículo, sí hubo un alza importante de las tasas de interés acompañada de un fenómeno de "credit crunch" en 1998, pero ambas tendencias fueron combatidas rápidamente con un cambio en la política monetaria y con medidas del gobierno en favor de las PME, las más perjudicadas por la contracción de la oferta de crédito. En consecuencia, después de culminar a más de $15 \%$ en 1998 , la tasa activa de base y las demás tasas bancarias disminuyeron hasta la actualidad (gráfica 2), por lo que la economía coreana experimentó una progresión de la monetización, una importancia creciente del crédito interno en relación con el PIB que refleja el papel siempre destacado de la banca comercial en la economía del país, así como ciertos cambios en la regulación de esta parte de la esfera financiera (gráfica 3).

En efecto, la banca comercial fondeada mediante las cuentas de depósito y ahorro convencionales siguió siendo el principal proveedor de crédito al sector privado y elevó su

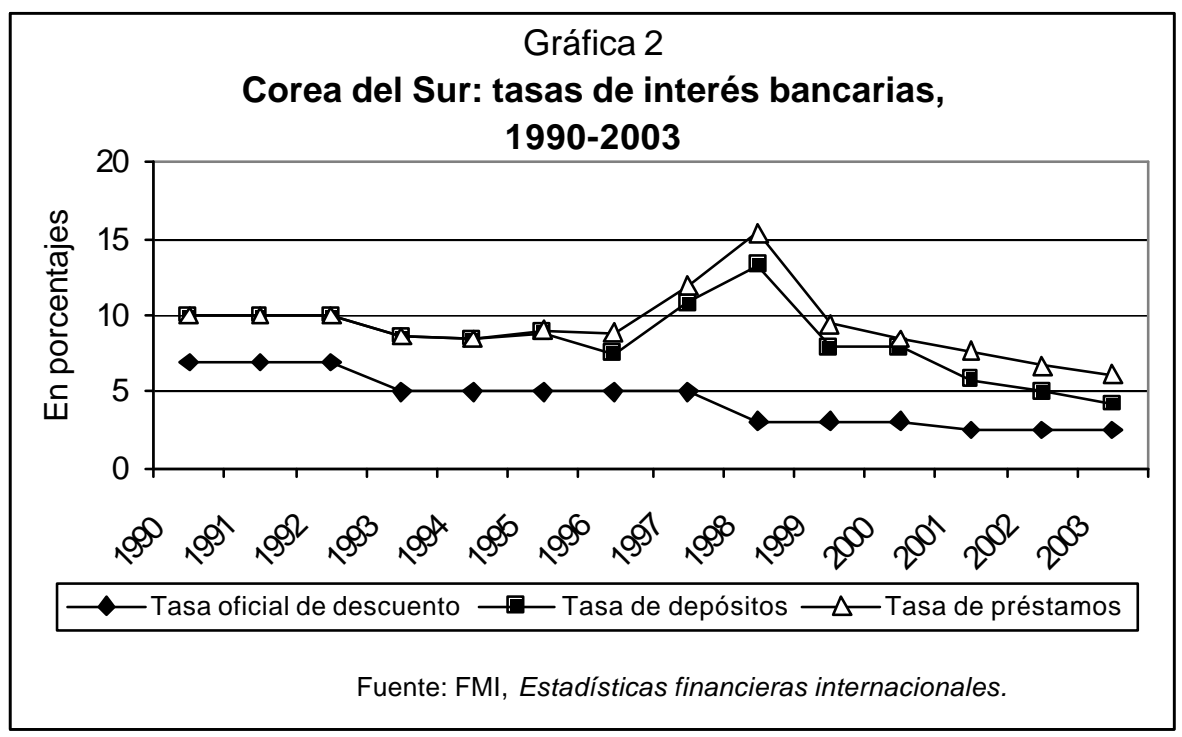


oferta de crédito en relación con el PIB, pero a la vez disminuyó su oferta de financiamiento proveniente de sus actividades de fideicomiso (gráfica 4): esta parte desreglamentada de sus actividades, que le permitía competir con las IFNB muy poco reguladas, ha sido drásticamente recortada después de la crisis.

Ahora bien, se ha producido entre $1997 \mathrm{y}$ la actualidad una modificación fundamental en la participación relativa de los diferentes tipos de destinatarios de estos créditos. La proporción de crédito orientado hacia las grandes empresas ha caído fuertemente mientras se elevaba la que recibían las PME y las familias. Ésta es hasta cierto punto una evolución que equipara la trayectoria del sistema bancario coreano con la que experimentaron años antes las economías más adelantadas de la OCDE: las grandes empresas encuentran financiamiento directo más "barato", recurriendo a las colocaciones de bonos en los mercados financieros locales o internacionales y los bancos tienen que desarrollar productos adecuados a otro tipo de clientela, las PME y los individuos. De hecho, la composición del financiamiento de los chaebols venía cambiando desde los ochenta, elevándose constantemente la participación de los bonos en su financiamiento externo en relación con el crédito bancario ${ }^{25}$ y los progresos en el desarrollo de este mercado (ver gráfica 5), en parte debido al propio rescate financiero y a la emisión de bonos públicos, favoreció un mejor ac- ceso de las empresas. Sin embargo, en el caso de Corea esta evolución ha sido profundizada y acelerada con la crisis financiera: en el marco de la reestructuración las grandes empresas han debido disminuir sus coeficientes de endeudamiento: así, la razón deuda/capital cayó de $400 \%$ en 1997 a $123 \%$ en 2003 , en el sector manufacturero. ${ }^{26}$

En consecuencia, tanto la banca comercial como otras IFNB han emprendido una reorientación de su oferta de crédito hacia las PME y las familias. El crédito a las familias, muy reducido todavía a inicios de los noventa debido a la importancia puesta por el modelo de desarrollo alrededor del financiamiento industrial, creció de manera muy rápida a partir de 1998-1999 (gráfica 6), elevándose a 45\% del total en 2002. De manera simultánea, la participación de las corporaciones en el total del crédito empresarial disminuía de $42 \%$ del total (1992) a $22 \%$ en $2001,{ }^{27}$ y se encontraría ahora en alrededor de $12 \%$ para los primeros seis bancos del sistema ${ }^{28}$ (ver gráfica 7 ).

La expansión extremadamente rápida del crédito a las familias culminó entre 2002 e inicios de 2003: si la banca comercial representa la mayoría de esta oferta, los demás proveedores - las empresas de tarjetas, las instituciones de ahorro y la aseguradoras, entre otras - también han participado de este auge, que hizo que el crédito hacia estos agentes económicos se multiplicara en 2.5 veces en

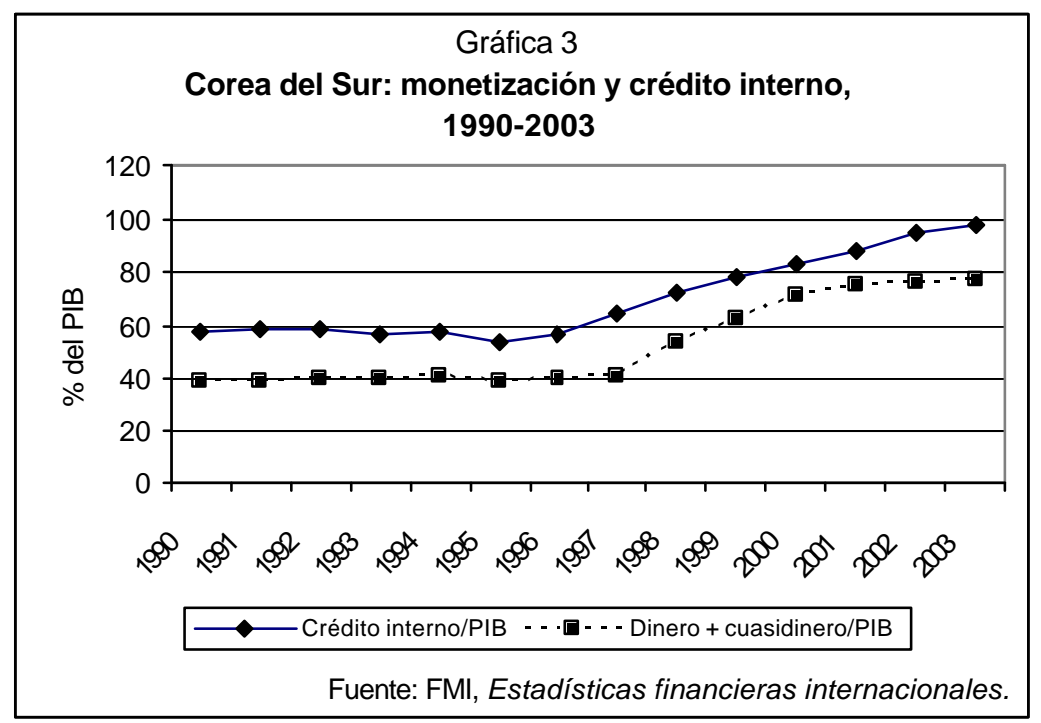



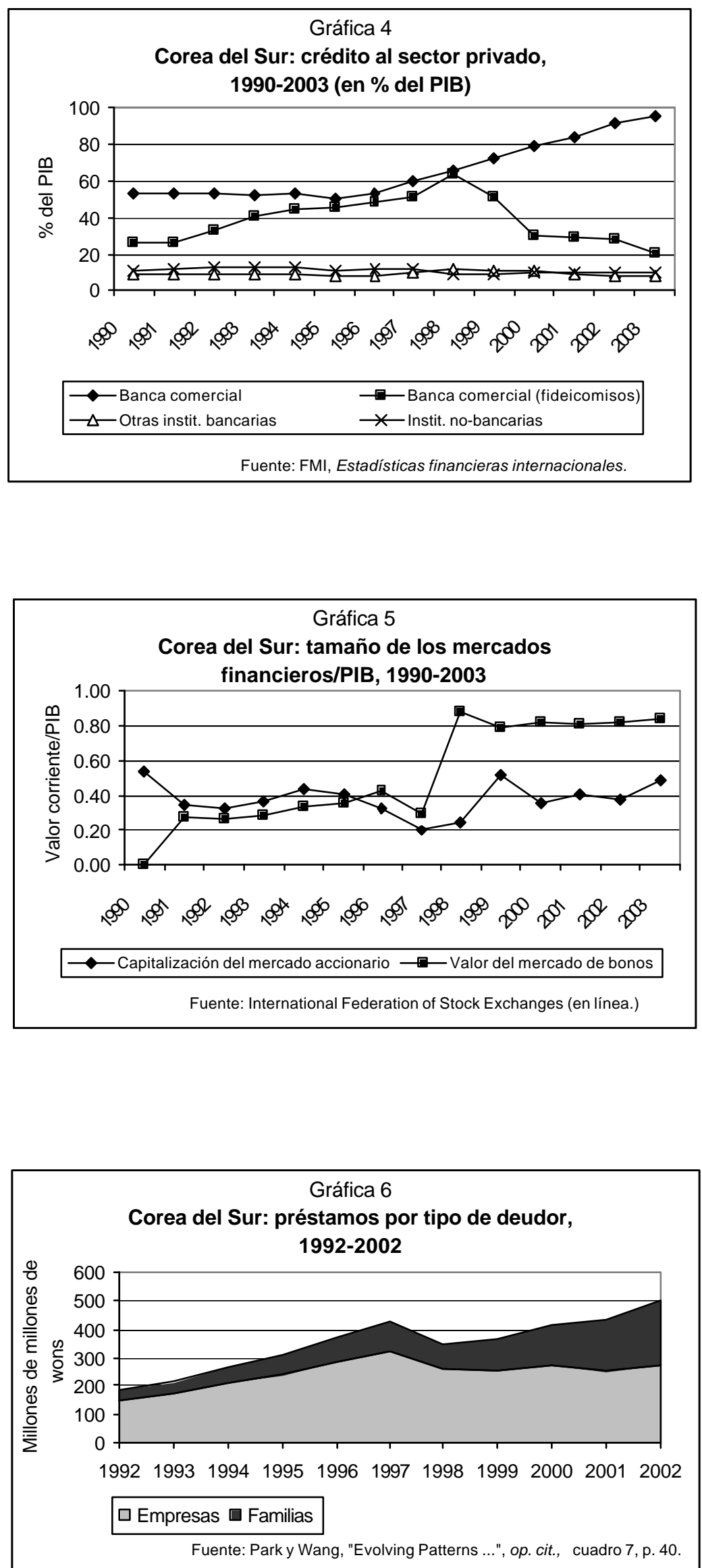

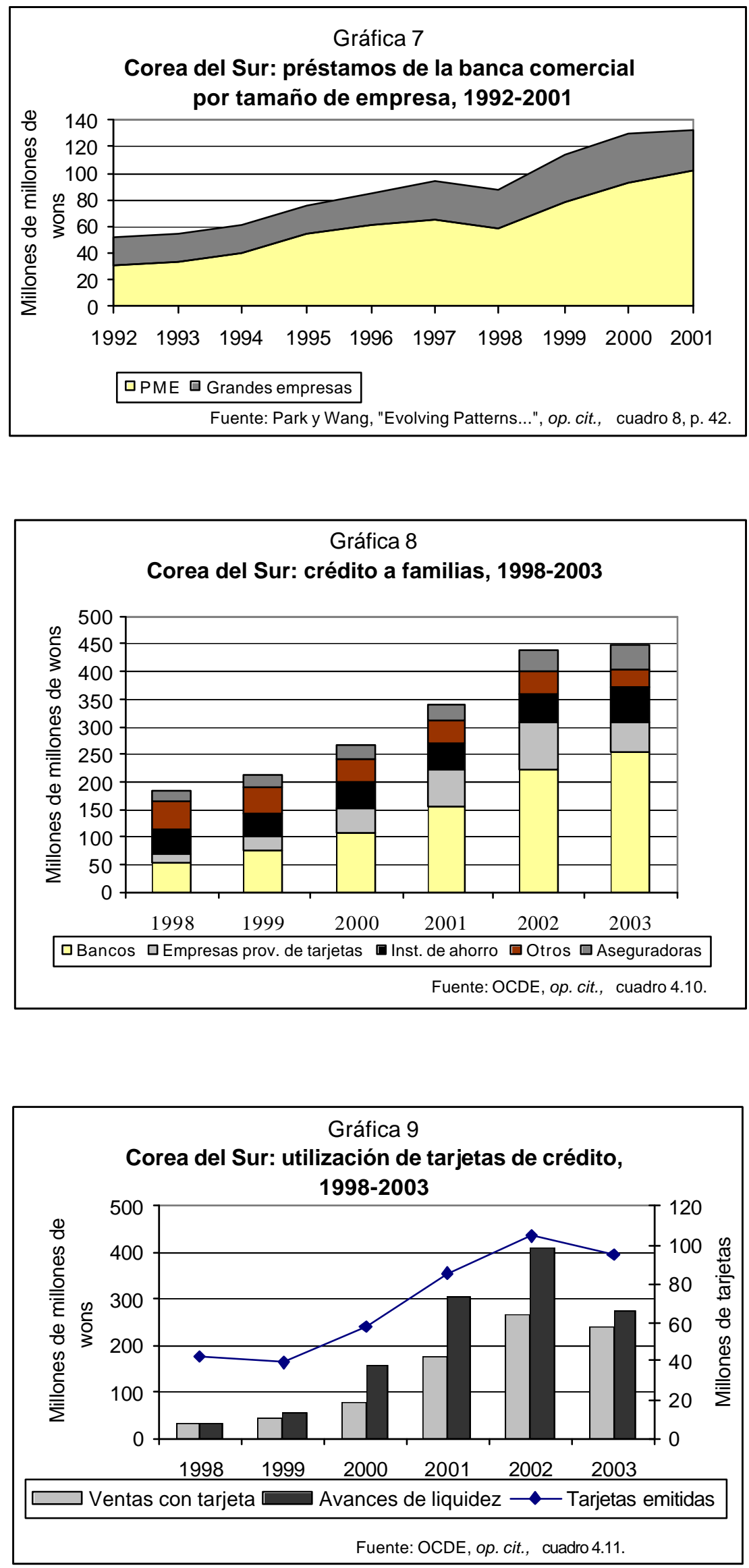
menos de cinco años (gráfica 8). Como consecuencia de ello, la deuda de las familias coreanas se elevó de $47 \%$ del PIB en 1997 a $70 \%$ en $2002,{ }^{29}$ a la vez que se incrementaban los problemas de pagos.

El crecimiento del crédito ha sido fuertemente acelerado por la expansión del uso de las tarjetas de crédito, facilitada por un proceso de desreglamentación y varios incentivos adicionales introducidos por el gobierno. El número de tarjetas en circulación pasó de 42 millones en 1998 a más de 104 millones en 2002 , cifra que cabe comparar con los 24 millones de personas que integran la población activa coreana, mientras que tanto las compras efectuadas con tarjeta como los avances de efectivo solicitados crecían a ritmo sostenido (gráfica 9). Los resultados en términos de incapacidad de pagar no se hicieron esperar mucho. Entre 2000 y 2004 casi 4 millones de individuos fallaron en el pago de este tipo de deudas. ${ }^{30}$

En suma, esta diversificación de la cartera de créditos de bancos e IFNB ha sido marcada por problemas de selección de clientes combinados con una reglamentación demasiado laxa que permitió la aceptación de riesgos excesivos. La banca comercial, donde una proporción significativa de los créditos ha sido otorgada con fines de adquisición de bienes inmuebles (vivienda), ha sufrido menos que las companías proveedoras de tarjetas independientes. La más grande de estas empresas, LG Card, afiliada de un poderoso chaebol, tuvo que ser rescatada con dinero público. Sin embargo, los resultados de la banca han sido afectados negativamente por la situación de sus afiliadas en este sector y ha debido reabsorber estas entidades y asumir sus pérdidas. Por último, esta crisis tuvo consecuencias macroeconómicas serias para Corea, pues generó una contracción del consumo interno que contribuyó decisivamente a la desaceleración económica experimentada por el país desde mediados del año 2003.

\section{Conclusión}

Aún cuando buscaba establecer relaciones más distantes entre el gobierno y las grandes empresas y entre éstas y el sistema bancario, la reestructuración corporativa y financiera coreana ha sido llevada a cabo bajo la tutela estatal. El sistema bancario, fuertemente apoyado por el Estado, ha salido de la crisis de sobreendeudamiento corporativo de manera bastante rápida y reemprendió el crecimiento, restableciendo su nivel de rentabilidad. Uno de los cambios más sobresalientes introducidos en el sistema después de la crisis es la participación extranjera, concentrada en particular en los bancos más grandes, y de la cual se espera una mayor eficiencia. Sin embargo, los nuevos problemas de cartera vencida que surgieron como producto del esfuerzo de diversificación de la cartera de créditos de la banca hacia el sector de las familias, muestran que queda todavía bastante camino que recorrer antes de que el sistema bancario coreano alcance niveles de eficiencia cercanos a los internacionales.

\section{Notas}

1 ocde, Economic Survey: Korea, París, 1998, p.7.

2 Zainal-Abidin Mahani, Kwanho Shin y Yunjong Wang, "Macroeconomic Adjustments and the Real Economy in Korea and Malaysia Since 1997", Working Paper 0307, Korea Institute for International Economic Policy, Seúl, junio de 2003.

3 La caída del PIB en 1998 excedió en mucho las previsiones del organismo internacional. Prevista en $1 \%$, la contracción del PIB fue realmente de 6.7\%, ibid., p. 17.

4 Las tasas de corto plazo, cercanas al $12 \%$ antes de la crisis, fueron elevadas a más de $30 \%$ en diciembre de 1997, ibid., p. 29.

5 Se dieron varias ampliaciones presupuestales destinadas a estimular la demanda, en particular a través del gasto social destinado a compensar los peores efectos del programa — desempleo y pérdida de ingresos para muchos asalariados-. Finalmente, el déficit fiscal alcanzó $4.2 \%$ del PIB en 1998.

6 Ibid., p. 50-53.

7 Su adopción fue facilitada por los antecedentes del gobierno coreano en materia macroeconómica, en particular por el equilibrio fiscal que prevaleció en los primeros noventa, y el bajo nivel de deuda del gobierno $-11 \%$ del PIB en 1997- que daba amplio margen para la aplicación de una política expansiva.

8 Chan-Hyun Sohn, Junsok Yang y Seung Beom Kim, "Liberalization Measures in the Process of Korea's 
Corporate Restructuring. Trade, investment and Capital Account Market Openings", Discussion Paper 02-11, Korea Institute for International Economic Policy, Seúl, noviembre de 2002.

9 Meredith Woo-Cumings, "Miracle as Prologue: the State and the Reform of the Corporate Sector in Korea", en Joseph Stiglitz y Shahid Yusuf (eds.) Rethinking the East Asian Miracle, World Bank-Oxford University Press, 2001, pp. 343-377 (cita p. 364).

10 Zainal-Abidin Mahani, Kwanho Shin y Yunjong Wang, "Macroeconomic Adjustments and the Real Economy in Korea and Malaysia Since 1997", op. cit., p. 56.

11 Un comité creado para este propósito estaba encargado de "evaluar la viabilidad de la reestructuración propuesta por las corporaciones, arbitrar las diferencias de opinión entre acreedores y, de ser necesario, modificar los planes de renegociación propuestos por los acreedores participantes", Meredith Woo-Cumings, "Miracle as Prologue: the State and the Reform of the Corporate Sector in Korea”, op. cit., p. 366.

12 Zainal-Abidin Mahani, Kwanho Shin y Yunjong Wang, "Macroeconomic Adjustments and the Real Economy in Korea and Malaysia Since 1997”, op. cit., p. 56-58.

13 Chan-Hyun Sohn, Junsok Yang y Seung Beom Kim, "Liberalization Measures in the Process of Korea's Corporate Restructuring...”, op. cit., p. 12.

14 Para una presentación detallada de las medidas y un análisis de sus efectos, ver Chan-Hyun Sohn, Junsok Yang y Seung Beom Kim, "Liberalization Measures in the Process of Korea's Corporate Restructuring...”, op. cit., p. 12.

15 Ibid., pp. 37 y 54.

16 ocde, Economic Survey:Korea, 2004, París, pp. 106-107.
17 Ibid., pp. 124-125.

18 Thomas Byrne, "The Korean Banking System Six Years After the Crisis", Korea's Economy, Korea Economic Institute of America, 2003, pp. 15-19, disponible en línea en http://www.keia.com/KoreaEc.htm.

19 La proporción de recursos recuperados varía ampliamente de una crisis financiera a otra, dependiendo de la gravedad de ésta y de la forma en que fueron distribuidos los apoyos entre las instituciones rescatadas.

20 Los dos últimos absorbieron recientemente dos instituciones que habían caído en manos de las autoridades como producto de su rescate, el Banco de Seúl y el banco Chohung. Thomas Byrne, "The Korean Banking System...", op. cit., p. 16.

21 oCDE, Economic Survey: Korea, 2004, París, p. 112.

22 Ibid., p. 113.

23 Financial Times, "Field day for foreigners in South Korea", 21/10/04.

24 Financial Times, "Seoul sells Woori and KT\&G stakes", 09/09/04.

25 Geneviève Marchini, "Reformas financieras y crisis bancaria en Corea del Sur", Problemas del desarrollo, vol. 31, núm. 123, octubre-diciembre de 2000, México, DF, pp. 79-105.

26 oCDE, Economic Survey: Korea, 2004, París, p. 106.

27 Haesik Park y Yunjong Wang, "Evolving Patterns of Corporate Financing in Korea", Discussion Paper 03 03, Korean Institute for International Economic Policy, Seúl, julio de 2003, pp. 40-42.

28 Thomas Byrne, "The Korean Banking System...", op. cit., p. 16

29 Ibid., p. 17.

30 ocDe, Economic Survey:Korea, 2004, París, p. 119.
La serie “Cuenca del Pacífico: retos y oportunidades para México" es una colección integrada por cinco volúmenes, bajo la coordinación general de Melba E. Falck Reyes.

Volumen 1. Economía y cultura en la Cuenca del Pacífico, editado por Geneviève Marchini.

Volumen 2. El modelo de desarrollo asiático. Relevancia para México, editado por Melba E. Falck Reyes y Roberto Hernández Hernández.

Volumen 3. Jalisco y su inserción en la Cuenca del Pacífico, editado por Dagoberto Amparo y Melba E. Falck Reyes.

Volumen 4. What's in a Name? Globalization, Regionalization, and APEC, editado por Arturo Santa Cruz.

Volumen 5. Agricultura en la Cuenca del Pacífico, editado por Roberto Hernández Hernández.

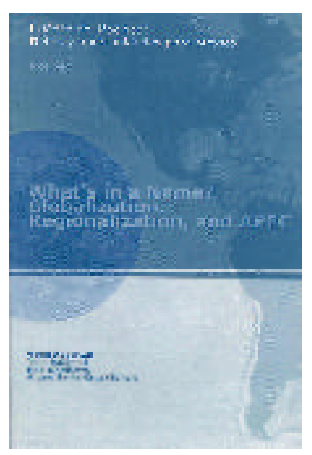

\section{Volumen 4. What's in a Name? Globalization, Regionalization, and APEC}

\author{
Vinod Aggarwal \\ John Ravenhill \\ Hadi Soesastro \\ Arturo Santa-Cruz (editor) \\ Primera edición, 2003 \\ Universidad de Guadalajara \\ Precio estudiantes \$130.00 \\ Precio público $\$ 260.00$
}

De venta en: librería el Kiosco, Centro Universitario de Ciencias Sociales y Humanidades, Av. Alcalde esquina Av. de los Mestros, edificio G, planta baja, Guadalajara, Jalisco 